\title{
Global Regulatory Strategies for Tobacco Control
}

Lawrence O. Gostin

Georgetown University Law Center, gostin@law.georgetown.edu

Georgetown Public Law and Legal Theory Research Paper No. 1034466

This paper can be downloaded free of charge from:

https://scholarship.law.georgetown.edu/facpub/481

http://ssrn.com/abstract=1034466

298 JAMA 2057-2059 (2007)

This open-access article is brought to you by the Georgetown Law Library. Posted with permission of the author. Follow this and additional works at: https://scholarship.law.georgetown.edu/facpub

3 Part of the Health Law and Policy Commons 


\section{Global Regulatory Strategies for Tobacco Control}

Lawrence O. Gostin, JD

N THE MID-20TH CENTURY, THE CIGARETTE WAS A CULtural icon in Western society-tobacco smoking was viewed as chic, promoted ubiquitously, and portrayed by sports and movie stars as an accoutrement of the good life. ${ }^{1}$ But by the close of the century, public and political perceptions were transformed by revelations about the tobacco industry's knowledge of the risks and its intent to deceive. Tobacco executives understood the health effects of smoking, the addictive quality of nicotine, and the toxicity of pesticides contained in cigarettes.

The ensuing regulation in North America and Western Europe had a salutary effect, even if smoking remains a pressing public health hazard. But in the 21st century, the tobacco industry has quietly moved its locus of activity to lucrative, emerging markets- the vast populations in Africa, Asia, Eastern Europe, and Latin America. The poorest, least educated, and sickest people on earth inhabit these regions. "Big Tobacco's" new marketing strategy will cause untold morbidity for the world's most vulnerable.

The Tobacco Pandemic. Smoking, the leading preventable cause of death globally, caused 5.4 million deaths in 2006 ( 1 in 10 adult deaths worldwide). ${ }^{2}$ The annual mortality rate is projected to double by 2020 . These deaths occur not only among smokers, but also among newborns of mothers who smoke and persons exposed to secondhand smoke. The burden of disease and death is rapidly shifting to low- and middle-income countries, with $84 \%$ of smokers now living in developing and transitional economy countries, more than half of them in Asia. If current trends continue, mortality rates in poor countries will increase precipitously because tobacco kills half of its regular users.

The global economic costs of tobacco are predicted to reach $\$ 500$ billion annually by 2010 . $^{3}$ Tobacco-related illness is the top health expenditure in many countries, particularly in China, which consumes more than 30\% of the world's cigarettes. ${ }^{3}$ Beyond the economic effects, smoking contributes to world hunger by diverting farmland from food production and displacing consumer purchases of life's necessities to maintain a tobacco addiction. At the same time, the 3 largest multinational cigarette companies have combined annual revenues exceeding $\$ 121$ billion. $^{4}$

Tobacco Control Regulation. The Framework Convention on Tobacco Control (FCTC), the first treaty negotiated under World Health Organization auspices, was adopted in 2003 and entered into force in $2005 .{ }^{5}$ The majority of countries (150) have ratified the treaty, with 3 densely populated countries conspicuously missing-Indonesia, Russia, and the United States. Global nongovernmental organizations associated with the United Nations (UN) networks such as the Framework Convention Alliance and Global Smokefree Partnership have set regulatory goals for FCTC implementation, which were adopted at the Second Conference of FCTC Parties, Bangkok, Thailand, in July $2007 .{ }^{6}$

A powerful, well-funded national agency to regulate tobacco can be highly effective. The US Supreme Court overturned comprehensive tobacco regulations because the Food and Drug Administration lacked the power. ${ }^{7}$ Currently, Congress is considering legislation to empower the Food and Drug Administration to regulate tobacco products. After a decade-long political fight, Kenya recently enacted the Tobacco Control Act, which establishes a strong tobacco control board. Government agencies authorized to create and enforce tobacco control rules can be a potent force for prevention, education, and treatment of nicotine dependence.

Advertising, Promotion, and Sponsorship. For tobacco companies to remain profitable, they must recruit new smokers to replace those who quit or die. Because most longterm smokers begin before 18 years of age, the youth market is most valuable. The industry spends inordinately on advertising, promotion, and sponsorship, and the United States alone spent $\$ 13.11$ billion in $2005 .{ }^{8}$ In developing countries, multinational companies advertise to induce experimentation among nonsmokers and stimulate consumer demand for international brands instead of local products. Simultaneously, companies promote "youth smoking prevention" campaigns as part of "corporate social responsibility," although they are ineffective and undermine effective tobacco control. While aggressively courting youth culture, the industry takes credit for youth prevention.

Cigarette advertisements are replete with text and images associating smoking with healthy, adventuresome, glamorous lifestyles, which mislead the public and imply that health warnings are exaggerated. Tobacco campaigns, more-

Author Affiliations: O'Neill Institute for National and Global Health Law, Georgetown University Law Center, Washington, DC; and Department of Health Policy and Management, Johns Hopkins Bloomberg School of Public Health, Baltimore, Maryland. Corresponding Author: Lawrence O. Gostin, JD, Georgetown University Law Center, 600 New Jersey Ave NW, Washington, DC 20001 (gostin@law.georgetown .edu). 
over, appeal to different demographics: fitness, wealth, and power for men; slimness, emancipation, sophistication for women; and youthful vigor, sexual attraction, and independence for adolescents. Companies entice teenagers by linking their brands to cartoon characters, giving away appealing clothing and free cigarettes, and sponsoring sports, music, film, and fashion. The industry asserts that promotional activities merely influence brand choice among adults. But research demonstrates that advertising increases consumption and is associated with the onset of youth smoking. ${ }^{9}$

Total bans on promotional activities are most effective in reducing consumption. Bans have been successfully implemented in Europe (Finland, France, and Norway) and Asia (India, Singapore, and Thailand). However, the FCTC allows tobacco-advertising regulations to conform to national constitutions. Most high courts do not afford "free speech" protection to tobacco advertisements because they have low informational value, are misleading, appeal to youth, and result in profound socioeconomic harms. An Australian federal court in New South Wales held that advertisements disputing the harmful effects of second-hand smoke were deceptive. ${ }^{10}$ Similarly, the Canadian Supreme Court recently upheld federal regulations banning misleading claims, youth marketing, "lifestyle" images, and sponsorship. ${ }^{11}$ The US Supreme Court stands virtually alone in the world in aggressively defending the constitutionality of tobacco advertising. ${ }^{12}$

The transnational legal implications of advertising bans are complex. When governments prevent or block messages on the Internet, telephone, or satellite television, communication is curtailed regionally or globally. The US Supreme Court will review whether states may regulate Internet or telephone sales of tobacco to ensure that retailers are licensed and cigarettes are not sold to minors. ${ }^{13}$ The FCTC conference is also planning a protocol on cross-border advertising regulations. In a global market, international cooperation is essential for effective regulation of tobacco advertising.

Health Warnings and Content Disclosure. Health warnings on cigarette packets are most effective if they cover at least half of the packet, convey the risks, rotate messages, and use images. Labeling increases awareness of the risks and vivid pictures are most likely to influence young smokers and the children of smokers. The 2001 European Union tobacco directive makes text warnings mandatory and pictures permissible; at least 14 countries have mandated vivid pictures of the harmful consequences of smoking. ${ }^{14}$

Cigarettes labeled light, low tar, or mild are deceptive because they are as hazardous as regular cigarettes. ${ }^{15}$ The European Union bans branding of cigarettes as light or mild. In a 2006 civil racketeering case, a US District Court ordered tobacco companies not to use these terms. Judge Kessler stated the industry "has marketed their lethal product with zeal, with deception, with a single-minded focus on their financial success, and without regard for the human tragedy or social costs." 16
Tobacco products are manufactured with hundreds of chemical additives, such as carbon monoxide, nitrogen oxides, hydrogen cyanide, and ammonia. Many additives are toxic, carcinogenic, or both, when burned. Compelled disclosure of contents can be effective in informing consumers and dissuading them from smoking. Consumers who see the numerous toxic substances in cigarettes may question the industry's motives and fear the health consequences. Government can go further by directly regulating the contents of tobacco products, such as the nicotine level and the number or amount of toxins.

Sales to Minors. Tobacco use among young people is pervasive, with $17.3 \%$ of students aged 13 to 15 years worldwide reporting current tobacco use. ${ }^{17}$ Approximately 82000 to 99000 children start smoking every day, with roughly half living in Asia. ${ }^{18}$ In China, $47 \%$ of boys and $12.8 \%$ of girls experiment with smoking. Tobacco is readily available to children, even in countries with legal prohibitions. The industry actively promotes youth smoking through advertising, free samples, vending machines, and candy or flavored cigarettes. In Indonesia, Philip Morris is introducing clove-flavored cigarettes, which have more tar and nicotine than any other Marlboro product.

The UN Convention on the Rights of the Child requires states to protect children from tobacco and ensure that their interests take precedence over those of the industry. The FCTC specifically requires states to prohibit sales to minors and ensure effective implementation. Countries have numerous regulatory tools at their disposal, such as banning sales to minors, smoking near schools, sweets and flavored cigarettes, and vending machines.

Smoke-free Environments. Exposure to environmental tobacco smoke is ubiquitous in many parts of the world. Approximately half the students surveyed in 132 countries reported exposure to smoke in public places and at home. ${ }^{5}$ The FCTC Conference of Parties, representing $80 \%$ of the world's population, established historic guidelines on smokefree environments. ${ }^{19}$ The Conference urged universal protection from environmental tobacco smoke, covering all indoor workplaces, indoor public places, and public transport, as well as outdoor public places "as appropriate." National legislation should (1) create a $100 \%$ smoke-free environment, recognizing there is no safe level of exposure; (2) engage civil society to support smoke-free laws; and (3) enforce, monitor, and evaluate the legislation.

In 2004, Ireland became the first country to enact national smoke-free legislation. Currently, $100 \%$ smokefree legislation protects more than 200 million people worldwide, including national laws in Afghanistan, Iran, Kenya, New Zealand, the United Kingdom, and Uruguay, and subnational laws in Argentina, Australia, Canada, North Korea, and the United States. ${ }^{20}$ Smoke-free laws offer multiple benefits: improved air quality, reduced morbidity and premature mortality, and a decrease in tobacco consumption. Public opinion strongly favors smoke-free laws, 
particularly among young people in the Americas, Europe, and eastern Mediterranean. ${ }^{21}$ Additionally, smoke-free laws have not had an adverse economic effect on bars and restaurants, as the tobacco and service industries had predicted. $^{22}$

Price and Taxation and Illicit Trade. Tax and price policies reduce smoking, particularly among the poor and the young. A $10 \%$ price increase reduces consumption by about $4 \%$ in high-income countries and $8 \%$ in low-income countries. ${ }^{18}$ Taxation also raises revenue, which can be used for effective tobacco prevention and cessation programs. The FCTC requires states parties to report cigarette tax rates and tobacco consumption trends. The World Bank proposes that taxes should account for two-thirds to four-fifths of the retail price of cigarettes.

The illicit trade in cigarettes—smuggling, bootlegging, unlawful manufacturing, and counterfeiting-is a global problem that is often linked to organized crime. Tobacco executives may even be complicit in this underground network. Problematically, as cigarette taxes increase, so does the underground economic response. The global illicit cigarette trade is estimated at nearly $11 \%$ (600 billion) of the 5.6 trillion cigarettes sold in 2006. Illicit trade makes international brands more affordable, reduces tax revenues by $\$ 40$ to $\$ 50$ billion annually, and enables smugglers to evade health regulations such as labeling requirements. ${ }^{6}$ Illicit trade increases the youth market because smuggling lowers cigarette prices and circumvents sales prohibitions to minors. The FCTC requires marking unit packets with the product's origin and, for domestic sales, a statement that they can be sold only in that country.

The FCTC Conference recently announced that the first FCTC protocol will cover illicit trade of tobacco products. A comprehensive system of international cooperation would track tobacco products, license bona fide suppliers and distributors, enhance enforcement, and create strict liability for manufacturers to pay taxes and duties.

Globalization: Exporting Tobacco. With stricter regulation and an increasing anti-tobacco culture, smoking rates in North America and Western Europe have plummeted. Tobacco executives have aggressively sought new markets in developing countries. The industry has been astonishingly successful as smoking worldwide is expected to massively increase, along with industry profits. The forces of globalization-unparalleled communication, transportation, and commerce-propel this trend. ${ }^{18}$

Many parties have been complicit in exporting tobacco to the poor. ${ }^{1}$ The industry promotes a popular smoking culture of glamour and allure. It uses sophisticated marketing to transition people from indigenous products to global, harmonized brands. The United States and other developed countries advance tobacco exports through diplomacy, economic sanctions, and bilateral trade agreements. The international community prioritizes trade liberalization over consumer protection. In the Thailand-Cigarette Case, the World
Trade Organization said Thailand had legitimate concerns about the health hazards of American cigarettes due to harmful additives, but ruled that an import ban was unnecessary because less trade-restrictive alternatives existed. ${ }^{6}$

The industry's success in exploiting poor people will have enduring, harsh health and economic consequences in lowand middle-income countries. However, civil society is fighting back through global regulatory strategies and new global initiatives by Michael Bloomberg and the Gates Foundation to prevent 100 million deaths from tobacco by $2020 .^{2}$ The imperatives of science, ethics, and human rights oblige society to reduce the burden of smoking, particularly among the disadvantaged. Tobacco marketing and commerce, with all their destructive force, do not deserve sociolegal protections, such as freedom of trade and speech.

Financial Disclosures: None reported.

\section{REFERENCES}

1. Brandt AM. The Cigarette Century: The Rise, Fall, and Deadly Persistence of the Product That Defined America. New York, NY: Basic Books; 2007.

2. WHO Tobacco Free Initiative. Facts and figures about tobacco. http://www .who.int/tobacco/framework/cop/facts_and_figures_about_tobacco.pdf. Accessed September 7, 2007.

3. Mackay J, Eriksen MP. The Tobacco Atlas. Geneva, Switzerland: World Health Organization; 2002.

4. World Health Organization. Tobacco and poverty: a vicious circle. http://www who.int/tobacco/communications/events/wntd/2004/en/wntd2004_brochure_en .pdf. Accessed September 7, 2007.

5. Roemer R, Taylor A, Lariviere J. Origins of the WHO framework convention on tobacco control. Am J Public Health. 2005;95(6):936-938.

6. Framework Convention Alliance. How big was the global illicit tobacco trade problem in 2006? Presented at: Second Conference of Parties to the WHO FCTC; July 2, 2007; Bangkok, Thailand.

7. Food and Drug Administration v Brown \& Williamson Tobacco Corp, 529 US $120(2000)$

8. Federal trade commission cigarette report for 2004 and 2005. http://www.ftc .gov/reports/tobacco/2007cigarette2004-2005.pdf. Accessed August 18, 2007. 9. Gilpin EA, White MM, Messer K, et al. Receptivity to tobacco advertising and promotions among young adolescents as a predictor of established smoking in young adulthood. Am J Public Health. 2007;97(8):1489-1495.

10. Australian Federation of Consumer Organisations v Tobacco Institute of Australia, 27 FCR 149 (1990).

11. Canada (Attorney General) v JTI-Macdonald Corp, 2007 SCC 30 (2007).

12. Lorillard Tobacco Co v Reilly, 533 US 525 (2001).

13. Rowe v New Hampshire Motor Transport Assn, 448 F3d 66 (2006).

14. The European Parliament and the Council. Directive 2001/37/EC on the approximation of the laws, regulations and administrative provisions of the member states concerning the manufacture, presentation and sale of tobacco products. Off J Eur Communities. 2001;18(7):L194/26-L194/34. http://www.ensp.org/files /directive_2001_37_ec.pdf. Accessibility verified September 28, 2007.

15. National Cancer Institute Fact Sheet. The truth about "light" cigarettes: questions and answers. http://www.smokefree.gov/Docs2/Truth_LightCigarettes Q\&A.pdf. Accessed September 7, 2007.

16. United States v Philip Morris, 449 F Supp 2d 1 (2006).

17. Prokhorov AV, Winickoff JP, Ahluwalia JS. Youth tobacco use: a global perspective for child health care clinicians. Pediatrics. 2006;118(3):e890-e903.

18. Jah P, Chaloupka FJ. Curbing the Epidemic: Governments and the Economics of Tobacco Control. Washington, DC: The World Bank; 1999.

19. World Health Organization. Protection From Exposure to Second-hand Tobacco Smoke: Policy Recommendations. Geneva, Switzerland: World Health Organization; 2007.

20. Global Voices for a Smokefree World: Movement Towards a Smokefree Future, Global Smokefree Partnership, 2007. http://www. globalsmokefreepartnership .org/files/members/files//82.pdf. Accessed October 11, 2007.

21. GTSS Collaborative Group. A cross-country comparison of exposure to secondhand smoke among youth. Tob Control. 2006;15:ii4-ii19.

22. Alamar B, Glantz SA. Effect of smoke-free laws on bar value and profits. Am J Public Health. 2007;97(8):1400-1402. 